OPPORTUNITIES FOR NURSES TO INCREASE PARENTAL HEALTH LITERACY: A DISCUSSION PAPER

Opportunities for nurses to increase parental health literacy: a discussion paper

Robyn Johnston, Cathrine Fowler, Valerie Wilson, and Michelle Kelly

Author Note

Robyn Johnston, RN, PhD student Faculty of Health, University of Technology, Sydney

Cathrine Fowler, RN, PhD, Faculty of Health, University of Technology, Sydney

Valerie Wilson, RN, PhD, Faculty of Health, University of Technology, Sydney

Michelle Kelly, RN, PhD, Faculty of Health, University of Technology, Sydney

Correspondence concerning this article should be addressed to Robyn Johnston, Faculty of

Health, University of Technology, Sydney, P.O. Box 123 Broadway, NSW, 2007

Email: Robyn.Johnston@student.uts.edu.au 


\title{
OPPORTUNITIES FOR NURSES TO INCREASE PARENTAL HEALTH LITERACY: A DISCUSSION PAPER
}

\begin{abstract}
Most families can access a range of health information and advice. Information and advice sources often include nurses, the Internet, social media, books, as well as family and friends. While the immediate aim may be to find information, it can also be to assist with parenting skills, solve parenting problems or as part of decision-making processes about their child's health. These processes are strongly influenced by the parent's level of health literacy. Health literacy describes a person's capacity to obtain and utilize health related information. Although there are numerous health literacy definitions all have clearly defined steps. These steps are: obtaining relevant information; then understanding this information; and finally being able to use the information to achieve the expected outcome.

Previous research has linked low levels of parental health literacy with poorer child health outcomes. Given this link, increasing health literacy levels would be advantageous for both families and health services. Nurses working with families are in a position to support the family to increase their health literacy through the use of a variety of strategies. This article outlines how health literacy can influence the way parents seek help when they are concerned about child health issues, the relevance of parental health literacy for nurses and suggests some tools that could be used to support the increase of health literacy.
\end{abstract}




\section{OPPORTUNITIES FOR NURSES TO INCREASE PARENTAL HEALTH LITERACY: A DISCUSSION PAPER}

\section{INTRODUCTION}

Children are dependent on their parents to seek help regarding their health. Parents are reliant on their knowledge and skills as to how to assist their children during episodes of illness or to ensure the child's continued wellbeing. The successful outcome of any help seeking episode or self-treatment of a child's illness can be influenced by the parent's level of health literacy. The Institute of Medicine of the National Academies (2004, p. 32) defines health literacy as:

... the degree to which individuals can obtain, process, and understand the basic health information and services they need to make appropriate health decisions.

In Australia, parents wanting to seek help are able to access a wide range of public health services, for example Child and Family Health Services (CFH), and General Medical Practitioners (Schmied et al. 2010). Additionally, some parents choose to seek help from the internet (Bouche \& Migeot 2008), family and friends (Curry et al. 2002) or parenting books (Moseley, Freed \& Goold 2011) before or as an alternative to contacting a health service. Irrespective of where the parent seeks help they can be exposed to medical terminology and acronyms they have never heard of or advised to undertake tasks they have never attempted such as taking a temperature, administering medication to their infant or using a breast pump. This can be especially challenging for first-time parents. Health literacy or the ability to access and understand basic health information is a fundamental aspect of health seeking skills. If health literacy is viewed as the accumulation of knowledge and skills regarding health, then like any knowledge or skill it can be learnt. 


\section{OPPORTUNITIES FOR NURSES TO INCREASE PARENTAL HEALTH LITERACY: A DISCUSSION PAPER}

Learning can occur through different sources including experience by successfully performing tasks; observing other people perform or demonstrate tasks, frequently described as vicarious experiences (Bandura 1977) ; or through hearing or reading how people dealt with similar situations. Additionally, learning can be supported through the use of a partnership approach with nurses where meaning can occur through discussion resulting in increased parenting confidence (Fowler et al. 2011). Nurses are well placed to assist parents increase their health literacy levels (Mayer 2011) and therefore improve health outcomes for not only the children but also their families.

\section{HEALTH LITERACY}

While health literacy is strongly influenced by literacy and numeracy skills, other influencing factors include: culture, education, age, language, occupation, reasoning (cognitive processing skills), vision, hearing and memory (Baker 2006; Sorensen et al. 2012). Assumptions about parental health literacy level based solely on literacy or education level (Adams et al. 2009) can be misleading and opportunities to clarify information or assist in enhancing health literacy abilities missed. For example, a first-time parent with university level qualifications may not be able to understand the language or numeric values used during a health consultation without relevant explanation and questioning. Nor can it be assumed that in developed countries, such as Australia, health literacy levels will always be at levels high enough to enable families to successfully seek help or deal with minor illnesses. To illustrate, as part of the 2006 Adult Literacy and Life Skills Survey (ALLS) the Australian Bureau of Statistics (2008) determined that $41 \%$ of adults surveyed had adequate or better health literacy skills; which means that $59 \%$ 
OPPORTUNITIES FOR NURSES TO INCREASE PARENTAL HEALTH LITERACY: A DISCUSSION PAPER

had lower than adequate levels of health literacy. Adequate or better level is regarded as the minimum required to allow individuals to meet the complex demands of everyday life.

Currently these is no one definition of health literacy with a literature review by Sorensen et al. (2012) locating17 different definitions but while the wording may be vary, all have clearly defined steps . The first is accessing relevant information; then understanding this information and finally being able to use the information to achieve the expected outcome and has been conceptualized in Figure 1. This conceptualization can assist in understanding the knowledge and skills required as part of health literacy.

\section{Figure 1 - Graphic representation of health literacy definition}

To achieve their desired health outcome or goal parents need to be able to successfully complete each step as outlined in Figure 1. While this process may seem relatively simple for nurses or for parents with a high level of confidence or self-efficacy (Bandura 1997) for others, barriers or a lack of skills or knowledge could result in a struggle or failure to complete the process. For first time parents who may never have used the health services in their neighborhood this lack of confidence or self-efficacy could result in confusion or frustration trying to locate, contact or navigate the health system.

Families wanting to access information online can encounter thousands of search engine results from a myriad of sources requiring them to judge the relevance and reliability of the information provided. For instance, searching for 'how to treat a temperature in babies' in a 


\section{OPPORTUNITIES FOR NURSES TO INCREASE PARENTAL HEALTH LITERACY: A DISCUSSION PAPER}

Google search, resulted in approximately $1,030,000$ sites $\left(14^{\text {th }}\right.$ January 2015$)$ while a search of 'teething in babies' resulted in over $1,230,000$ sites $\left(14^{\text {th }}\right.$ January 2015$)$. Regardless of where families access information, they will be exposed to often unfamiliar medical terminology or acronyms that they have not heard before and therefore may not know the meaning. Being able to understand medical terminology creates the conditions that enable parents to process health information. Families who have accessed health services and do not understand specific terminology can attempt to discuss the meaning with the health professional; in contrast, families who access online information will not have this option.

The final step, being able to action any information or recommendation such as a management plan, can be uncomplicated or challenging. The degree of complexity is frequently dependent on parents having previous exposure to the prescribed activity or information. An example of this is an infant feeding plan for a first-time mother which includes post breastfeeding breast expression. Not only does the mother need to breastfeed her baby, she now has to learn how to assemble, use and clean a breast pump and manage the safe storage of any expressed breastmilk.

As parents acquire new knowledge regarding their child's health, so too can their health literacy level increase. This increase is frequently inconsistent as Baker (2006, p. 878) notes 'health literacy may vary depending upon the medical problem being treated'. Understanding the important role of health literacy when working with families creates an understanding that parents may demonstrate adequate health literacy regarding some childhood illnesses, health 


\section{OPPORTUNITIES FOR NURSES TO INCREASE PARENTAL HEALTH LITERACY: A DISCUSSION PAPER}

literary regarding a newly diagnosed health issue may be inadequate. This can result in parents failing to understand or comprehend the child's care requirements placing the child at risk.

\section{Relevance of health literacy for nurses working with children and their families.}

Children and their families are seen by health services in both acute and community settings and whilst care is focused on the child, it is the parent who has to action any care plan and their ability to do so is potentially determined by their level of health literacy. Research has linked low levels of parental health literacy to children's poorer health outcomes (DeWalt \& Hink 2009).

Low health literacy levels has been associated with reduced use of health services (Berkman et al. 2011), and inappropriate use of services such as attending emergency departments for non-urgent issues (Kubicek et al. 2012), difficulties contacting after-hours medical providers (Yin et al. 2012) and actioning health referrals (Jimenez et al. 2013). In addition, Kaufman et al. (2001) found that low health literacy was associated with low levels of breastfeeding.

Research into the impact of parental health literacy on childhood asthma has identified that parents with low health literacy are less likely to report their child as being in good health (Dunn-Navarra et al. 2012) and in many instances they will say that their asthmatic child is in poor or fair health. In addition, low parental health literacy has been associated with a higher need for asthma medication, a lower likelihood of an asthma plan being in place or followed and more visits to the emergency department (DeWalt et al. 2007; Macy et al. 2011; Shone et al. 2009). Other examples of the impact of low health literacy levels relate to medication administration. According to the Australian Institute of Health and Welfare (2011) between 
OPPORTUNITIES FOR NURSES TO INCREASE PARENTAL HEALTH LITERACY: A DISCUSSION PAPER

2009-2010, 168 children aged 0-4 years were admitted to hospital with accidental poisoning or inappropriate exposure to nonopioid analgesics, antipyretics and anti-rheumatics. In 110 of these cases the drug used was 4-aminophenol derivatives e.g. paracetamol, which is commonly recommended to treat childhood fever. In the U.S.A. Dart et al. (2009) examined paediatric fatalities related to medications and found that 118 were related to over-the-counter cough and cold medications. Of these 103 were associated with non-prescription drugs or combined nonprescriptive and prescriptive drugs. Most of the children affected were under 2 years of age with adults being the most common person administrating the medication (Dart et al. 2009). Low health literacy has been found to be related to difficulties understanding the relationship between weight and dosage (Gribetz \& Cronley 1987), determining the correct dosage (Kumar et al. 2010a), actual dosage errors (Samuels-Kalow, Stack \& Porter 2013) and the use of non-standard measuring devices (Yin et al. 2007) such as teaspoons. Parents with low health literacy levels can experience difficulties in identifying the active ingredient in medications such as in cough and cold medications that could contain acetaminophen (Yin et al. 2013). This lack of awareness can lead to unsafe dosing as parents could use two different medications without realizing that they contain the same ingredient (Dart et al. 2009).

If improving health outcomes for children and their families are of central concern for health services, then health literacy is a very relevant issue. Health literacy becomes an essential consideration when developing health strategies, education and providing preventative health programs. 
OPPORTUNITIES FOR NURSES TO INCREASE PARENTAL HEALTH LITERACY: A DISCUSSION PAPER

\section{Opportunities to increase parents' health literacy.}

As it is beyond the scope of this article to discuss opportunities to increase health literacy across all health services that work with children and their families, Child and Family Health (CFH) services, New South Wales (NSW), will be used as an example as to when these opportunities could arise. The CFH service is based on a primary health care model with the aim of early identification and implementation of intervention strategies to ameliorate risk factors to enhance child health and wellbeing (NSW Department of Health 2009). This is achieved through offering child health checks, developmental screening and surveillance, support for new parents, comprehensive psychosocial assessments to identify families at risk and the provision of health education (NSW Department of Health 2011; NSW Kids and Families 2013). At the present time all families in NSW with a new baby are offered a home visit. The NSW Department of Health (Centre for Epidemiology and Evidence 2012) reported that in $201060 \%$ of families with infants aged 0-11 months continued to regularly access CFH services.

While the number of times families contact the $\mathrm{CFH}$ service and the mode of interaction i.e. face-to-face, over the telephone or in group situations (NSW Department of Health 2009) will vary. Figure 2 provides a typical contact point pattern. 


\section{OPPORTUNITIES FOR NURSES TO INCREASE PARENTAL HEALTH LITERACY: A DISCUSSION PAPER}

Figure 2: Typical contact points between families and NSW CFH services

$\mathrm{CFH}$ nurses could use these contact points to opportunistically assist parents to increase their health literacy levels in regards to child health knowledge and skills. This would potentially increase parental confidence and competence and as shown in Figure 2 (Point A) these opportunities can commence in the antenatal period. Previous research has shown that families do search for information, electronically or via books, prior to the birth of their baby (Carolan 2007; Khoo et al. 2008; Plantin \& Daneback 2009). A face-to-face opportunity occurs during antenatal parent classes normally provided by midwives with a focus on pregnancy, the birthing process, breastfeeding and the initial postnatal period. These classes could be utilized by $\mathrm{CFH}$ nurses to provide information, both verbally and written, on various topics including $\mathrm{CFH}$ services and infant behaviour in the first few weeks of life. Face-to-face sessions could also provide an opportunity for the $\mathrm{CFH}$ nurse to: introduce the $\mathrm{CFH}$ service; answer any parental concerns or questions; explain information that the family may have previously accessed; and as Carolan (2007) found to provide a context for the information. This interaction with the parents may result in an increase in their knowledge of their local area CFH services and health vocabulary; but there are disadvantages as the parents' focus can be predominantly on the birth process (Renkert \& Nutbeam 2001) limiting the success of such a strategy.

In the postnatal period, families are encouraged to contact $\mathrm{CFH}$ services for a routine child health check or to seek help regarding a specific issue as shown by points B, C and D in Figure 2. Although these encounters provide opportunities to increase health literacy, it could be 
OPPORTUNITIES FOR NURSES TO INCREASE PARENTAL HEALTH LITERACY: A DISCUSSION PAPER

argued that to do so the nurse would first need to know a parent's current health literacy level. At the present time there are several tools to measure health literacy including the Test of Functional Health Literacy in Adults (TOFHLA) (Hironaka \& Paasche-Orlow 2007) which measures reading fluency and the Rapid Estimate of Adult Literacy in Medicine (REALM) which is a word recognition and pronunciation test (Baker 2006). The time taken to complete these tools ranges from 2-to-3 minutes for the REALM to 25 minutes for TOHHLA (von Wagner et al. 2009). However, Baker (2006 concludes that neither test measures an individual's full capacity; rather they test selected domains while von Wagner et al. (2009) concludes that the current tools do not measure health literacy as currently defined. Due to this lack of agreement regarding the usefulness and accuracy of tools measuring health literacy, staff could use a consultative process to determine health literacy.

As part of a consultative process CFH nurses use a partnership approach (Davis \& Day 2010) to explore the presenting issue and together develop a management or care plan to allow parents to meet their goals. Rather than test parent's health literacy this practice aims to ascertain their knowledge regarding a specific issue; for example what do they know about vomiting in babies or the role of CFH services? These findings inform the nurse about additional information requirements to support an increase in the parent's child health knowledge and skills. An important consideration when providing this oral information is the nurses' awareness of the language used as parents with low health literacy can be challenged by a number of factors including big words, complex terms, doctor language and medical terms (Sentell et al. 2013, p. 4). While the use of some medical terms cannot always be avoided as this can assist in 
OPPORTUNITIES FOR NURSES TO INCREASE PARENTAL HEALTH LITERACY: A DISCUSSION PAPER

orientating parents to an identified issue, the word meanings must be conveyed as part of the conversation (Roter 2011). CFH service settings can also provide a safe environment for parents to learn experientially with the assistance of the $\mathrm{CFH}$ nurse; for example how to settle or soothe a crying baby. The mother is then able to practice these techniques at home reinforcing knowledge and skills; if the outcome is successful an increase in maternal self-confidence or self-efficacy may occur.

First-time parenting groups and topic specific groups such as a group with a focus on toddler behaviour, provides contact points between parents and $\mathrm{CFH}$ services. These groups have a health promotion, health education or anticipatory guidance focus on a variety of topics including babies safe sleeping practices, immunisation, child development and play, and the introduction of solid foods (National Child Health and Wellbeing Subcommittee 2011). Rather than being purely didactic in nature, these groups offer parents different learning experiences that aim at increasing child health knowledge and skills and therefore health literacy. As discussed earlier, learning can be facilitated using different approaches of vicarious experiences or verbal persuasion(Bandura 1977). Instead of the CFH nurse being the facilitator, it is the other mothers within the group that provide vicarious experiences from which other mothers can learn. For instance a mother whose baby has started dribbling describes how the baby developed a rash due to the saliva and how she treated it. Mothers whose babies have not yet reached that stage can learn what a dribble rash looks like and how it can be treated, therefore increasing their child health knowledge and health literacy. 


\section{OPPORTUNITIES FOR NURSES TO INCREASE PARENTAL HEALTH LITERACY: A DISCUSSION PAPER}

Targeted educational programs have been frequently trialed as part of research or quality projects to address identified issues where low health literacy has impacted on child health outcomes. An example is an education strategy used to decrease emergency department attendance for common childhood illnesses using a self-help book to target families with low health literacy; this resulted in a reduction of visits and increased parent confidence (Herman \& Jackson 2010). While a project using plain language pictograms decreased the incidence of parental medication dosing errors (Yin et al. 2008); and the distribution and discussion of asthma education materials during an emergency department visit by nurses lead to increased asthma knowledge (Macy et al. 2011).

Previous research has shown that parents do not always remember what was discussed or recommended following medical consultations (Mccarthy et al. 2012; Schillinger et al. 2003) or may not be able to understand brochures or information sheets (Chappuy et al. 2012). They may also need assistance to read instructions or forms (Kalichman, Pellowski \& Chen 2013), or understand a service referral process (Jimenez et al. 2013). Checking with parents that they understand fact sheets or instructions enables an improved adherence to management/treatment plans. A key strategy is to avoid asking parents if they have understood what has been discussed as this closed question can result in a 'yes' response even if they do not understand. Instead using the 'teach-back' method is recommended (DeWalt et al. 2010) by asking parents to recall what was discussed or to outline the agreed management plan. If medications are involved then asking the parent to repeat the instructions and checking that their dosing technique is correct is essential. 


\section{OPPORTUNITIES FOR NURSES TO INCREASE PARENTAL HEALTH LITERACY: A DISCUSSION PAPER}

Nurses working in $\mathrm{CFH}$ services are in a unique position of being able to work both within their community and with other health partners, such as maternity and paediatric services, to enhance health literacy through the interactions we have with families. Working in partnership with other services in the provision of education expands the number of opportunities to support an increase parent health literacy. It is important for nurses to consider where the opportunities arise in their practice context and how these can be used to enhance health literacy.

\section{DISCUSSION}

It can be argued that nurses working with children and their families already have programs in place to increase health literacy through the provision of health education. While this may be common in regard to planned health education sessions, if nurses want to increase parental health literacy and therefore improve children's health outcomes they need to be ready to utilize every contact as an opportunity to increase health literacy. Achieving this increase will require that nurses use the appropriate tools and techniques. As a result of contact with health services families are often provided with information sheets or brochures but as shown in the IOM (2004) health literacy definition, families have to be able to understand the information. A lack of understanding may result in a family not being able to action the information provided, and the expected outcome not being achieved. Further, if families identify that their anticipated outcome of a health contact has not been met or they are dissatisfied with the health service, they are less likely to use that service in the future, (Janicke, Finney \& Riley 2001).

The Australian Commission on Safety and Quality in Health Care (2014, p. 43) states that to enable people to be able to know how to maintain their health, interact with health services or 
OPPORTUNITIES FOR NURSES TO INCREASE PARENTAL HEALTH LITERACY: A DISCUSSION PAPER

understand their diagnosis and treatment they need information that is clear, focused and usable. In addition, information provided has to be evidence-based (Australian Commission on Safety and Quality in Health Care 2014, p. 43). To enable this to occur, services working with children and their families need to review current documents to ensure the material meet these criteria. As parents with low health literacy can have difficulty understanding complex information it is essential that services ensure printed materials are easy-to-understand. While the intended audience is the most appropriate judge of this printed material, there are guidelines available to assist in the development such as Simply Put from the Centers for Disease Control and Prevention (2009). Another recommendation for readability is to develop information materials with a reading range between $6^{\text {th }}$ and $7^{\text {th }}$ grade (MedlinePlus 2013). Prior to trialing materials with the intended audience, there are several online tools that can be used to test readability such as the Flesch-Kincaid Readability Test, the Fry Readability Graph, the Gunning 'FOG' Readability Test (FOG), and the Simple Measure of Gobbledygook Readability Formula (SMOG) (Centers for Disease Control and Prevention 2009, p. 28).

With families increasing use of the internet to search for information to assist with decision making (Bouche \& Migeot 2008; Bouwan et al. 2010; Curry et al. 2002; Plantin \& Daneback 2009; Walsh et al. 2012) it highlights the need and responsibility to ensure that health service websites are appropriate for parents with low health literacy and contain the kinds of information parents are seeking (using the best sources of evidence). Being able to judge if a website is trustworthy and the information relevant can be difficult for first-time parents, especially when they are confronted with over a million options following a simple search so they may need to be 
OPPORTUNITIES FOR NURSES TO INCREASE PARENTAL HEALTH LITERACY: A DISCUSSION PAPER

assisted by nurses through recommendations of suitable and reputable websites (Walsh et al. 2012).

Gaining an understanding of a parent's health literacy capacity and then providing appropriately targeted resources could significantly reduce the risk of adverse health events. An example of nurses ensuring that education is reflective of this strategy is the provision of health education to manage a febrile child. Amongst strategies recommended as part of this session could be the appropriate use of over-the-counter medications such as paracetamol. If the nurse providing this education does not include a practical demonstration of how to calculate the correct dose, dispense the medication and discuss how often it can be given, then the parents could be left feeling confused and the possibility of errors in administration may result.

Transition period to parenthood can be difficult and often confusing. At the same time that parents are learning about their child, they also need to learn how to respond to episodes of illness and where, if required, they can seek help or advice. Parents do not immediately acquire health literacy following the birth of their baby but it can be learnt with the support of health services. Nurses are well positioned to take a parent's health literacy into consideration during every contact point and when developing resources that will be provided to families.

\section{CONCLUSION}

Low levels of parental health literacy are identified as being linked to poorer health outcomes for children. Parental health literacy level is a significant issue for nurses working with families. Health literacy is central to the provision of care, development of health strategies, education and the provision of preventative health programs. Ensuring that tools, printed information and 
OPPORTUNITIES FOR NURSES TO INCREASE PARENTAL HEALTH LITERACY: A DISCUSSION PAPER

education support a health literacy learning process will avoid causing confusion or errors; and can assist families gain parenting confidence during health seeking episodes.

Due to the interaction that already exists, nurses working with children and their families are well placed to utilize opportunities to provide an enabling environment to support families in increasing their levels of health literacy. Awareness of the contributing factors; processes and enablers regarding health literacy need to be appreciated and understood by nurses and health services. 


\section{OPPORTUNITIES FOR NURSES TO INCREASE PARENTAL HEALTH LITERACY: A DISCUSSION PAPER}

\section{REFERENCES}

Adams, R.J., Stocks, N.P., Wilson, D. \& Hill, C.L. 2009, 'Health literacy a new concept for general practice?', Australian Family Physician, vol. 38, no. 3, pp. 144-7.

Australian Bureau of Statistics 2008, Health Literacy, Australia, 2006, cat. no. 4233.0, Canberra, Retrieved from http: //www.ausstrats.abs.gov.au/austats/subcriber.nsf/0/73ED158C6B14BB5E CA257420011AB83/\$File/42330_2006.pdf

Australian Commission on Safety and Quality in Health Care 2014, Health literacy: taking action to improve safety and quality, 978-1-921983-62-7, Australian Commission on Safety and Quality in Health Care, Sydney. Retrieved from http://www.safetyandquality.au/wpcontent/uploads/2014/08/Health-Literacy-Taki.

Australian Institute of Health and Welfare 2011, Australian hospital statistics 2009-10. Health services series no. 40. Cat. no. HSE 107, Canberra.

Retrieved from http://www.aihw.gov.au/WorkArea/Download.aspx?id=10737418865

Baker, D.W. 2006, 'The meaning and the measure of health literacy', Journal of General Internal Medicine, vol. 21, pp. 878-83. doi: 10.1111/j.1525-1497.2006.00540.x

Bandura, A. 1977, Social Learning Theory, Prentice-Hall, New Jersey.

Bandura, A. 1997, Self-efficacy: The Exercise of Control, W.H. Freeman and Company, New York, USA. Berkman, N.D., Sheridan, S., Donahue, K.E., Halpern, D.J. \& Crotty, K. 2011, 'Low health literacy and health outcomes: an updated systematic review', Annals of Internal Medicine, vol. 155, no. 2, pp. 97-107. 


\section{OPPORTUNITIES FOR NURSES TO INCREASE PARENTAL HEALTH LITERACY: A DISCUSSION PAPER}

Bouche, G. \& Migeot, V. 2008, Parental use of the internet to seek health information and primary care utilisation for their child: a cross-sectional study. doi: 10.1186/1471-2458-8-300

Bouwan, M.G., Teunissen, Q.G.A., Wijburg, F.A. \& Linthorst, G.E. 2010, "Doctor Google' ending the diagnostic odyssey in lysosomal storage disorders: parents using internet search engines as an efficient diagnostic strategy in rare diseases', Arch Dis Child, vol. 95, pp. 642-4. doi:10.1136/adc.171827

Carolan, M. 2007, 'Health literacy and the information needs and dilemmas of first-time mothers over 35 years', Journal of Clinical Nursing, vol. 16, pp. 1162-72. doi:10.1111/j.1365-2702.2006.01600.x

Centers for Disease Control and Prevention, C. 2009, Simple Put, a guide for creating easy-to-understand materials, 3rd edn, Centers for Disease Control and Prevention. Retrieved from http://www.cdc.gov/healthliteracy/pdf/Simply_Put.pdf

Centre for Epidemiology and Evidence 2012, NSW Mothers and Babies 2010., NSW Ministry of Health, Sydney. Retrieved from http://www.health.nsw.gov.au/hsnsw/Publications/mothers-andbabies-2010.pdf

Chappuy, H., Taupin, P., Dimet, J., Claessens, Y.E., Treluyer, J.-M. \& Cheron, G. 2012, 'Do parents understand the medical information provided in pediatric emergency departments? A prospective multicenter study.', Acta Paediatrica, vol. 101, pp. 1089-94. doi:10.1111/j.13652702.2006.01600.x

Curry, M.D., Mathews, H.F., Daniel, H.J., Johnson, J.C. \& Mansfield, C.J. 2002, 'Beliefs about and responses to childhood ear infections: a study of parents in Eastern North Carolina', Social Science \& Medicine, vol. 54, pp. 1153-65. doi:10.1016.S0277-9536(01)00086-7 


\section{OPPORTUNITIES FOR NURSES TO INCREASE PARENTAL HEALTH LITERACY: A DISCUSSION PAPER}

Dart, R.C., Paul, I.M., Randall Bond, G., Winston, D.C., Manoguerra, A.S., Palmer, R.B., Kauffman, R.E., Banner, W., Green, J.L. \& Rumack, B.H. 2009, 'Pediatric fatalities associated with over the counter (nonprescription) cough and cold medications', Annals of Emergency Medicine, vol. 53, no. 4, pp. 411-7. doi:10.1016/j.anneergmed.2008.09.015

Davis, H. \& Day, C. 2010, Working in Partnership: The Family Partnership Model, Pearson Education, London.

DeWalt, D.A., Callahan, L.F., Hawk, V.H., Broucksou, K.A., Hink, A., Rudd, R. \& Brach, C. 2010, Health literacy universal precautions toolkit, AHRQ, Rockville, MD.

DeWalt, D.A., Dilling, M.H., Rosenthal, M.S. \& Pignone, M.P. 2007, 'Low parental literacy associated with worse asthma care measures in children', Ambulatory Pediatrics, vol. 7, no. 1, pp. 25-31.

DeWalt, D.A. \& Hink, A. 2009, 'Health literacy and child health outcomes: a systematic review of the literature', Pediatrics, vol. 124, pp. S265 - S74 doi:10.1542/peds.2009-1162B

Dunn-Navarra, A.-M., Stockwell, M.S., Meyer, D. \& Larson, E. 2012, 'Parental health literacy, knowledge and beliefs regarding upper respiratory infections (URI) in an urban Latinon immigrant population', Journal of Urban Health; Bulletin of the New York Academy of Medicine, vol. 89, no. 5, pp. 848-60. doi :10.1542/peds.2009-1162B

Fowler, C., Dunston, R., Lee, A., Rossiter, C. \& McKenzie, J. 2011, 'Reciprocal learning in partnership practice: an exploratory study of a home visiting program for mothers with depression', Studies in Continuing Education. doi 10.1080/0158037X.2011.61800

Gribetz, B. \& Cronley, S.A. 1987, 'Underdosing of acetaminopen by parents', Pediatrics, vol. 80, no. 5, pp. 630-3. 


\section{OPPORTUNITIES FOR NURSES TO INCREASE PARENTAL HEALTH LITERACY: A DISCUSSION PAPER}

Herman, A. \& Jackson, P. 2010, 'Empowering low-income parents with skills to reduce excess pediatric emergency room and clinic visits through a tailored low literay training intervention', Journal of Health Communication, vol. 15, pp. 895-910. doi10.1080/10810730.2101.522228

Hironaka, L.K. \& Paasche-Orlow, M.K. 2007, 'The implications of health literacy on patient-provider communication', Arch Dis Child, vol. 93, pp. 428-32.

Institute of Medicine of the National Academies 2004, Health literacy: a prescription to end confusion, The National Academies of Science Retrieved from http://www.nap.edu/catalog/10883.html

Janicke, D.M., Finney, J.W. \& Riley, A.W. 2001, 'Children's health care use, a prospective investigation of factors related to care-seeking', Medical Care, vol. 39, pp. 990-1001.

Jimenez, M.E., Barg, F.K., Guevara, J.P., Gerdes, M. \& Fiks, A.G. 2013, 'The impact of parental health literacy on the early intervention referral process', Journal of Health Care for the Poor and Undeserved, vol. 24, no. 3, pp. 1053-62. doi:10.1353/hpu.2013.0141

Kalichman, S., Pellowski, J. \& Chen, Y. 2013, 'Requesting help to understand medical information among people living with HIV and poor health literacy', AIDS Patient Care and STDs, vol. 27, no. 6, pp. 326-32.doi:10.1089/apc.2013.0056

Kaufman, H., Skipper, B., Small, L., Perry, T. \& McGrew, M. 2001, 'Effect of literacy on breast-feeding outcomes', Southern Medical Journal, vol. 94, no. 3, pp. 293-6.

Khoo, K., Bolt, P., Babi, F., Jury, S. \& Goldman, R. 2008, 'Health information seeking by parents in the internet age', Journal of Paediatrics and Child Health, vol. 44, pp. 419-23.doi :10.1111/j/14401754.2008.01322.X 


\section{OPPORTUNITIES FOR NURSES TO INCREASE PARENTAL HEALTH LITERACY: A DISCUSSION PAPER}

Kubicek, K., Liu, D., Beaudin, C., Supan, J., Weiss, G., Lu, Y. \& Kipke, M.D. 2012, 'A profile of nonurgent Emergency Department use in an urban Pediatric Hospital', Pediatric Emergency Care, vol. 28, no. 10, pp. 977-84. doi :10.1097/PEC.0b013e31826c9aab

Kumar, D., Sanders, M., Perrin, E.M., Lokker, N., Patterson, B., Gunn, V., Finkle, J., Franco, V., Choi, L., Rothman, P.L., (2010). Parental Understanding of health information: health literacy, numeracy and the Parental Health Literacy Activities Test (PHLAT), Academic Pediatrics, 10, 309-316

Macy, M.L., Davis, M.M., Clark, S.J. \& Stanley, R.M. 2011, 'Parental health literacy and asthma education delivery during a visit to a community-based Emergency Department, a pilot study', Pediatric Emergency Care, vol. 27, no. 6, pp. 469-74.

Mayer, G. 2011, 'Health literacy: an opportunity for nurses to lead by example', Nursing Outlook, vol. 59, pp. 59-60. doi:10.1016/j.outlook.2011.01.006

MedlinePlus 2013 How to write easy-to-read health materials, U.S. National Library of Medicine, Retrieved from: http://www.nlm.gov/medlineplus/etr.html

Mccarthy, D.M., Waite, K.R., Curtis, L.M., Engel, K.G., Baker, D.W. \& Wolf, M.S. 2012, 'What did the doctor say? Health literacy and recall of medical instructions', Medical Care, vol. 50, no. 4, pp. 277-82. doi10.1097/MLR0b013e318241e8e1

Moseley, K.L., Freed, G.L. \& Goold, S.D. 2011, 'Which sources of child health advice do parents follow?', Clinical Pediatrics, vol. 50, no. 1, pp. 50-6. doi:10.1177/0009922810379905

National Child Health and Wellbeing Subcommittee 2011, National Framework for Universal Child and Family Health Services, Commonwealth Goverment Canberra, Australia, viewed 29 January 2015, Retrievef from http://www.health.gov.au/internet/main/publishing.nsf/Content/natfram-ucfhs 


\section{OPPORTUNITIES FOR NURSES TO INCREASE PARENTAL HEALTH LITERACY: A DISCUSSION PAPER}

NSW Department of Health 2009, NSW Health/Families NSW Supporting Families Early Packagematernal and child health primary health care policy, NSW Department of Health, North Sydney, NSW. Retrieved from http://www0.health.nsw.gov.au/policies/pd/2010/pdf/PD2010_017.pdf

NSW Department of Health 2011, Child and Family Health Nursing Professional Practice Framework 2011-2016, NSW Department of Health, North Sydney, NSW. Retrieved from http://www.health.nsw.gov.au/nursing/projects/Publications/child-and-family-health-practiceframework.pdf

NSW Kids and Families 2013, NSW Kids and Families Information Bulletin regarding the revised Child Personal Health Record (Blue Book) 2012/2013 IB2013_028, Ministry of Health, NSW, North Sydney, NSW, viewed 16 January 2015. Retrieved from http://www.0.health.nsw.gov.au/policies/ib/2013/pdf/IB2013_028.pdf

Plantin, L. \& Daneback, K. 2009, 'Parenthood, information and support on the internet. A literature review of research on parents and professionals online', BMC Family Practice, 10: 34. doi: $10.1186 / 1471-2296-10-34$

Renkert, S. \& Nutbeam, D. 2001, 'Opportunities to improve maternal health literacy through antenatal education: an exploratory study', Health Promotion International, vol. 16, no. 4, pp. 381-8.

Roter, D.L. 2011, 'Oral literacy demand of health care communication: challenges and solutions', Nursing Outlook, vol. 59, no. 2, pp. 79-84. doi:10.1016/j.outlook.2010.11.005

Samuels-Kalow, M.E., Stack, A.M. \& Porter, S.C. 2013, 'Parental language and dosing errors after discharge from the pediatric Emergency Department', Pediatric Emergency Care, vol. 29, no. 9, pp. 982-7. 


\section{OPPORTUNITIES FOR NURSES TO INCREASE PARENTAL HEALTH LITERACY: A DISCUSSION PAPER}

Schillinger, D., Piette, J., Grumbach, K., Wilson, C., Daher, C., Leong-Grotz, K., Castro, C. \& Bindman, A.B. 2003, 'Closing the loop, physician communication with diabetic patients who have low health literacy', Archive Internal Medicine, vol. 163, pp. 83-90.

Schmied, V., Homer, C., Kemp, L., Thomas, C., Fowler, C. \& Kruske, S. 2010, 'The nature and impact of collaboration and integrated service delivery for pregnant women, children and families', Journal of Clinical Nursing, vol. 19, pp. 3516-26. doi:10.1071/AH13195

Sentell, T., Dela Cruz, M.R., Hee Heo, Y. \& Braun, K. 2013, 'Health literacy, health communication challenges, and cancer screening among rural Native Hawaiian and Filipino women', Journal of Cancer Education, vol. 28, no. 2, pp. 325-34. doi:10.1007/s13187-013-0471-3

Shone, L.P., Conn, K.M., Sanders, L.M. \& Halterman, J.S. 2009, 'The role of parent health literacy among urban children with persistent asthma', Patient Education and Counselling, vol. 75, pp. 368-75. doi:10.1016/j.pec.2009.01.004

Sorensen, K., van den Brouche, S., Fullam, J., Doyle, G., Pelikan, J., Slonska, Z. \& Brand, H. 2012, 'Health literacy and public health: a systematic review and integration of definitions and models', BMC Public Health, 12:80. doi: 10.1186/1471-2458-12-80

von Wagner, C., Steptoe, A., Wolf, M.S. \& Wardle, J. 2009, 'Health lieracy and health actions: a review and a framework from health psychology', Health Education \& Behavior, vol. 36, no. 5, pp. 86077. doi:10.1177/109019818322819

Walsh, A.M., Hyde, M.K., Hamilton, K. \& White, K.M. 2012, 'Predictive modelling: parents' decision making to use online child health information to increase their understanding and/or diagnose or treat their child's health', BMC Medical Informatics and Decision Making, 12.144. doi:

$10.1186 / 1472-6947-12-144$ 


\section{OPPORTUNITIES FOR NURSES TO INCREASE PARENTAL HEALTH LITERACY: A DISCUSSION PAPER}

Yin, H.S., Dreyer, B.P., Foltin, G.L., van Schaick, L. \& Mendelsohn, A.L. 2007, 'Association of low caregiver health literacy with reported use of nonstandardized dosing instruments and lack of knowledge of weight-based dosing', Ambulatory Pediatrics, vol. 7, no. 4, pp. 292-98.

Yin, H.S., Dreyer, B.P., van Schaick, L., Foltin, G.L., Dinglas, C. \& Alan, L. 2008, 'Randomized controlled trial of a pictogram-based intervention to reduce liquid medication dosing errors and improve adherence among caregivers of young children', Archives of Pediatris \& Adolescent Medicine, vol. 162 , no. 9 , pp. 814-22.

Yin, H.S., Dreyer, B.P., Vivar, K.L., MacFarland, S., vanSchaick, L. \& Mendelsohn, A.L. 2012, 'Perceived barriers to care and attitudes towards shared decision-making among socioeconomic parents: role of helath literacy', Academic Pediatrics, vol. 12, no. 2, pp. 117-24.

Yin, H.S., Mendelsohn, A.L., Nagin, P., Van Schaick, L., Cerra, M.E. \& Dreyer, B.P. 2013, 'Use of active ingredient information for low socioeconomic status parents' decision-making regarding cough and cold medications: role of health literacy', Academic Pediatrics, vol. 13, no. 3, pp. 229-35. 
OPPORTUNITIES FOR NURSES TO INCREASE PARENTAL HEALTH LITERACY: A DISCUSSION PAPER

Figure 1 - Graphic representation of health literacy definition

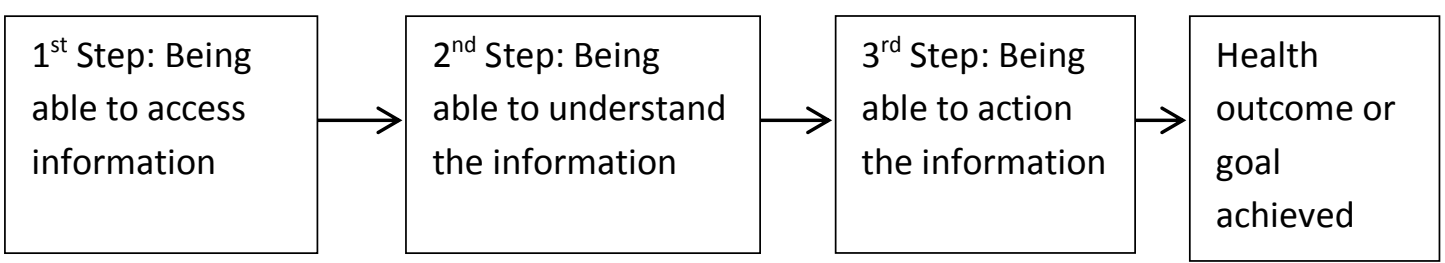


OPPORTUNITIES FOR NURSES TO INCREASE PARENTAL HEALTH LITERACY: A DISCUSSION PAPER

Figure 2: Typical contact points between families and NSW CFH services

Printed information regarding $\mathrm{CFH}$ services available in Maternity or on website

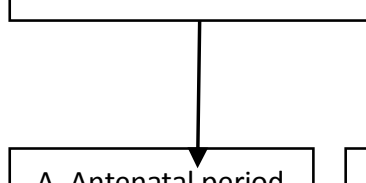

A. Antenatal period Family attends antenatal parent education

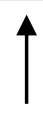

Nurse could attend antenatal classes to provide overview of CFH services

Printed information regarding $\mathrm{CFH}$ services or health education provided and explained orally

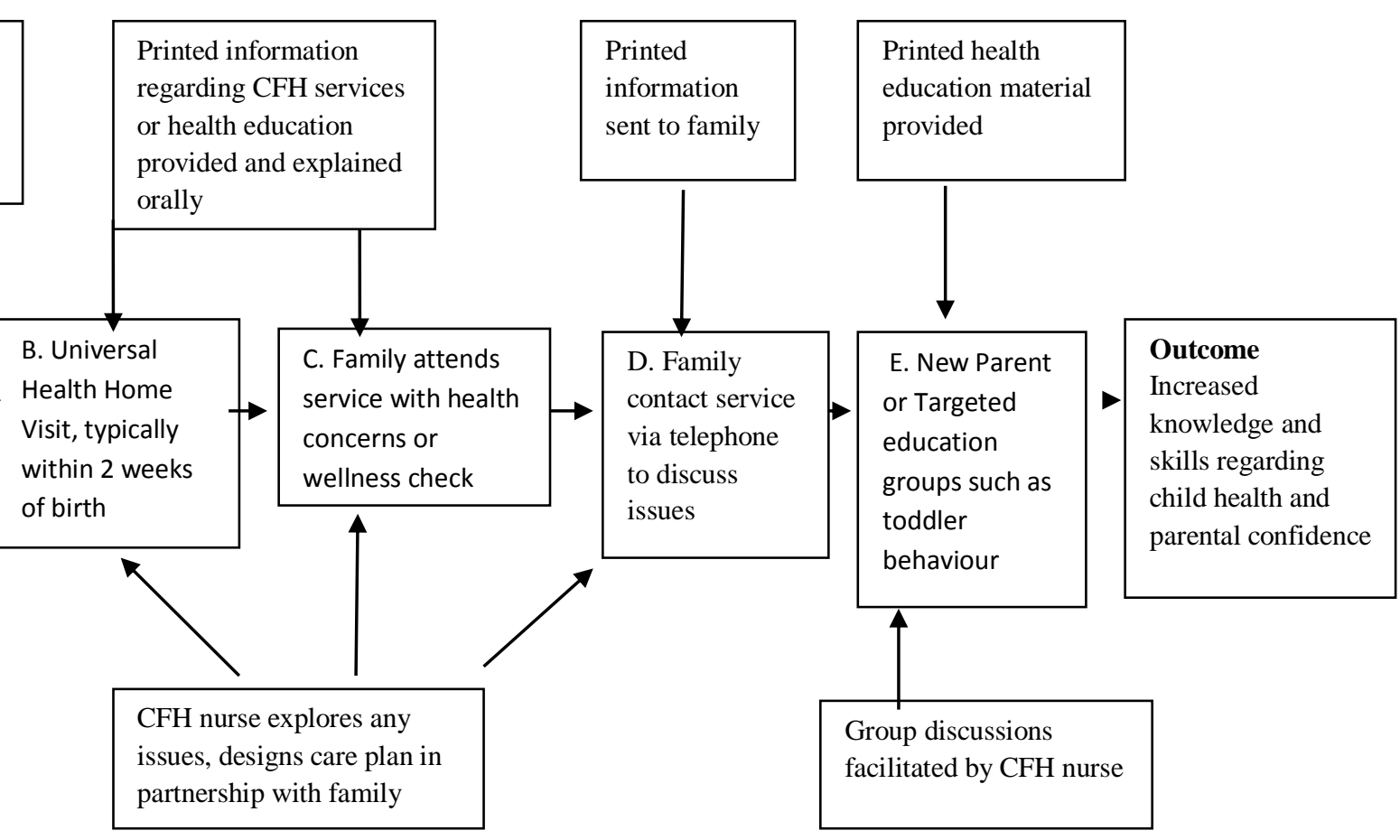

